\title{
Conception of Modernization Transformation of National Traditional Sports
}

\author{
Jianhui Li \\ Department of Physical Education, Aba Teachers University, Wenchuan Sichuan, 623002, China
}

Keyword: National Traditional Sports, Modernization,Transformation, Conception.

\begin{abstract}
Under the natural state, Chinese national traditional sports has always realized slow development for a long time. Confronted by the consistent collision and extrusion of modern western sports, traditional sports must realize the modernization transformation for the bigger development, which gradually changes from being closed to open. During the process, Chinese national traditional sports must maintain the tolerant and open attitude, further to let Chinese national traditional sports to go out and integrate into the world. In this paper, it illustrates the basic characteristics of national traditional sports' transformation of modernization, analyzes the basic conditions for the transformation of modernization and also puts forward several conceptions for the modernization transformation of national traditional sports.
\end{abstract}

\section{Introduction}

Under the general background that China enters the new normal, economy, society and culture have accelerated the transformation and upgrading, so as to realize the transformation from tradition to modernization. Chinese traditional sports originates from the Chinese civilization with a long history. So far, it has become one quite important component of Chinese traditional culture. Under the new circumstance, Chinese national traditional sports must establish in the local situations, positively face the world and actually integrate itself into the global sports dominated by western sports, dedicates itself to seeking a new route to realize the modernization transformation and tries to occupy a position in the global sports.

\section{Basic Characteristics of Modernization Transformation of Chinese National Traditional Culture}

According to the cultural structure theory, Chinese national traditional culture can be divided into three layers, respectively are physical cultural layer, system cultural layer(manifested as sports system) and behavior cultural layer.

The first layer is the physical cultural layer, namely to completely transform from the agricultural culture to industrial culture. In the cultural field, national traditional sports have the unique characteristics of mystery and simplicity. That's because these races usually possess extremely peculiar natural resources, such as the landscape, river and vegetation. They are the most abundant and excellent tourism resources in the modern society. Thus, cultural tourism of traditional sports in minority areas can be fully developed, which becomes the focus for the minority areas to develop the tourism. For instance, the national sports of Yunnan Li nationality--climbing a mountain of swords and suffering a sea of flames, it attracts tourists from all corners of the world by its thrill, uniqueness and excitement, thus it obtained quite good profits. March Festival of Bai in Dali, International Beach Festival of Tujia Nationality in Enshi, Hubei and dragon-boat race on Water-splashing Festival of Yunnan Xishuangbanna have offered quite good stages for the development of local economic culture. 
The second layer is the system cultural layer, namely to transform from blood relationship between clan and kinship to the urban defamiliarization. In the traditional agricultural society, Chinese minorities have always been generally mixed, small settlement, which not only expresses the lifestyle and fashion of all minority areas, but also promotes the production of local minorities' clan and kinship. In the traditional agricultural society, people usually lived with three or four generations under one roof, who all worked diligently for the same economic production unit. Affected by the big wave of industrial civilization, clan and kinship generated in the traditional agricultural society were affected, thus the social relations of minorities could only be transited to more flexible and urbanization interpersonal relationship.

The third layer is the behavior cultural layer, namely to transform from focusing on etiquette and advocating harmony to focus on competitiveness development. Chinese national traditional sports culture has always been famous for the nature, simpleness, heavy local flavor and advocation of etiquette. In the current society advocating competition and Law of the Jungle, some minority areas in China have positively developed tourism economy with strong ethnic characteristics. The local economy has obtained considerable development. Besides, the vision has also been broadened. For instance, the famous folk dance "Datiao" of Yi nationality and western disco were simultaneously performed on the stage of the Torch Festival, which actually broke through so-called rules and obtained quite good economic profits and social profits. These two dances with totally different cultural connotations appeared on the same stage, besides, they were both recognized by the audiences. It proves that Chinese national traditional sports culture has already transformed from focusing on the rite to practical development.

\section{Foundations for Chinese National Traditional Sports to Realize the Modernization Transformation}

Firstly, it needs the strong support and full promotion of the governmental departments. Under the actual situation that Chinese minorities' traditional sports has developed quite slowly and it is hard to carry out the modernization transformation, related governmental departments should offer strong support and positive promotion for the modernization transformation of national traditional sports. During the overall process of developing the sports, the competitive sports and national traditional sports coexist. Although Chinese sports is still dominated by the competitive sports, with the successive policies published by local governments in recent years, it can directly or indirectly promote the local minority traditional sports to transform to the modernization. For instance, International Climbing Festival of Mountain Tai and International Kite Festival of Weifang have enjoyed higher and higher reputation. On the basis of obtaining good economic profits for the local areas, it has also promoted related sports to realize the transformation of modernization.

Secondly, it needs strong foundation of mass. Once lack of strong mass base, local national traditional sports will absolutely not maintained in the long run and must vanish in the history. Some national traditional sports have already circulated among the people for thousands of years, which have quite good mass base, especially in local villages. Meanwhile, during recent years, with the consistent improvement of people's material standard of living, citizens have also been increasingly inclined to cultivate themselves and maintain physical and psychological health. Under the circumstance, some long-lost national traditional sports return to the life of citizens. It can be seen that, whether it possesses powerful mass base is the important condition for national traditional sports to survive and transform to the modernization.

Thirdly, it needs to positively invigorate national traditional culture. The national traditional culture can be considered as the key foundation for the existence of Chinese national traditional sports and maintenance of good development. If the national traditional culture can be invigorated, it can absolutely promote local national traditional sports to complete the transformation of modernization, which can naturally promote the local national traditional sports to realize development and expand. During recent years, the Party and the nation have attached much importance to the development of cultural undertakings including the national traditional culture, which offers huge political supports 
for the development of national traditional culture. Naturally, it offers strong guarantee for Chinese national traditional sports to realize the transformation of modernization.

\section{Several Conceptions to Promote Chinese National Traditional Sports to Implement the Transformation of Modernization}

\section{Promoting the Transformation of Modernization of Traditional Sports Contents}

Chinese cultural treasure possesses colorful social cultural forms, including philosophy, religion, literature, medicine and social custom. The national traditional sports is also a quite important sub-system of Chinese traditional culture. The profound national traditional sports culture is not merely embodied in practice, but also reflected on the cultural layer. Therefore, in the practice of national traditional sports, it should not only perform the national character, but also perform the characteristics of tradition and times. In order to make national traditional sports more complete and systematic, it should construct the contents, further to promote itself to realize the transformation of modernization.

\section{Promoting the Transformation of Modernization of Traditional Sports Culture}

Under the overall situation of globalization of world economy, Chinese national traditional sports culture has quite big possibilities to seek similarities while reserving the differences. Therefore, due to the global cultural openness and communication, all nations cannot keep their culture closed to the outside world for a long time. Otherwise, they will be at a standstill. Especially with the big development of modern information technology, culture of all nations is promoted to rely on each other. For instance, Dongba Jump characterized by Li Nationality of China, Naadam Fair characterized by Mongol nationality, Waving Dance Festival characterized by Tujia, Dragon-boat Race characterized by Miao, Drum-beating Dance characterized by Zhuang, Li, Dong and Bouyei nationality, girls chasing and snatching sheep characterized by Kazak, Bixiu characterized by Zang, wrestling activity developed between Mongol and Korean nationality, all these are quite festive folk games. There are also Lion Dancing, Dragon Dancing, Stilts and Yangko at the same time. During the process of activities, they are accompanied by songs and dances. Due to quite enthusiastic atmosphere and prominent style, they possess quite dense national characteristics and joyful atmosphere. It is worth proving that, during the consistent circulation and evolution of traditional sports, the minorities have consistently refined and reformed these activities, who fully give up the cultural dross and all kinds of bad habits of the feudal age, carry forward the artistic values of national traditional sports, and also enrich and develop those sports. It shows that, as long as those local traditional sports of China give full play to their rich cultural values, they will be accepted and recognized by the public, and then they will obtain sustainable existence and development under the fierce collision and conflict with the western sports, further to consistently re-understand, reform and improve themselves. In the future society, it is a modern society where multiple culture can coexist. As long as the traditional sports culture of Chinese minorities is full of vitality, it can face the world, survive and develop in the diversified cultural tide.

\section{Promoting the Modernization Transformation of Traditional Sports Inheritance Way}

The inheritance of Chinese minorities' traditional sports mainly relies on mutual imitation. As a matter of fact, the inheritance way has a quite low efficiency and rate of popularization. Considerable national traditional sports are even lost or extinct during the process of inheritance. Nowadays, the inheritance way of Chinese traditional sports is no longer limited to the single imitation of folk people, which adopts quite standard, systematic and specialized way to pass on traditional sports. Firstly, specific sports schools or sports training organizations impart the knowledge of modern sports, and also carry out sports training. Besides, a handful of professionals have specifically been engaged in the researches on the teaching of related national traditional sports, further to promote the study of such sports to obtain satisfactory development. However, currently, China has some specialized 
sports colleges to guide the teaching of modern sports, sports teaching in all comprehensive colleges and universities is dominated by the modern sports. Among so many traditional national sports, only well-known national traditional sports have been included in the teaching scope of sports major in colleges and universities, such as martial arts. Few can be included in the sports classroom of colleges and universities or standard and scientific national sports teaching in specialized sports colleges. In order to better promote Chinese traditional sports to realize the transformation of modernization, it should comprehensively standardize the inheritance way of Chinese national sports or set up specialized traditional sports courses in colleges or universities, or positively cultivate related talents interested in teaching national traditional sports, so as to consistently improve the inheritance efficiency of national traditional sports and fatherly promote the popularization of Chinese national traditional sports.

\section{Promoting the Modernization Transformation of Traditional Sports Manifestation Pattern}

Currently, the major manifestation pattern of Chinese traditional sports focuses on entertainment and ornamental value, which is close to the daily life of the minorities, with quite dense cultural atmosphere. Nowadays, the worldwide popular modern sports mainly emphasize on competitiveness, which conforms to the value of current times. We should comprehensively explore the competitive potentials of national traditional sports and let these sports to attract more attentions by competitive sports events. Although a lot of Chinese national traditional sports have been widely passed on in local areas and obtained quite good mass base, they are usually spread among the people who are interested in the national traditional sports and have the access to the sports. Modern sports mainly adopts the way of commercial operation and present sports for the public by different ways, such as big poster, advertisement, animation and sculpture. Therefore, in order to realize the transformation of modernization, national traditional sports must find the features closed to the market rule. Standing on the commercial operation, it can promote the traditional sports to realize the transformation of modernization. In order to promote China to realize the industrialization of national traditional sports, it should promote those sports events of national traditional sports which are suitable for the marketing operation. By commercial operation, it can form powerful social influence and economic profits. Meanwhile, by making hot news and stimulating sports medias to make large-scale propaganda and promotion of less popular national traditional sports, it can let them to be recognized by the market, such as Taekwondo of South Korea and Japanese karate, further to realize the transformation and development smoothly.

\section{Conclusion}

In conclusion, national traditional sports is the distinct manifestation of Chinese national culture in the domain of sports, which have a lot of quite valuable condensed cultural wealth. With the further acceleration of globalization, traditional sports of China has been ruthlessly squeezed by western sports. In order to survive and develop, Chinese traditional sports must deeply recognize the urgency to realize the transformation of modernization, look advantages of western sports in the face, learn from it modestly and make innovations and reform. Only by this way, can Chinese national traditional sports have new vitality and vigor under the new background of times.

\section{Acknowledgement}

This paper is the school-level key subject, Serial No. ASA15-03.

\section{References}

[1] Lu Kaizhi. Thoughts of Modernized Development of Chinese National Sports, Career Horizon (the second half of the month), 2008 (3). 
[2] Xu Caitong. Explorations of Modernization Transformation of Chinese National Sports, Journal of Wuhan Institute of Physical Education, 2008 (4)

[3] Xu Lin. Researches on the Diversified Traditional Sports Culture of Chinese Minorities in the New Period, Journal of Hebei Institute of Physical Education, 2009 (2) .

[4] Wu Feng. On Transformation and Development of National Traditional Sports from the Perspective of Marketing Operation, Sports and Exercise, 2011(4).

[5] He Hongliang. Development of National Traditional Sports under the Vision of Cultural Inheritance--Modernization and Globalization, Contemporary Sports Technology,2014 (12).

[6] Yin Jilin, Li Naiqiong. Dilemma and Enlightenment of Modernization Transformation of Chinese National Traditional Sports Culture, Journal of Xi'an Institute of Physical Education, 2016 (1). 